\title{
Migrant Digital Space: Building an Incomplete Map to Navigate Public Online Migration
}

\author{
Vasiliki Makrygianni, Abmad Kamal, Luca Rossi, \\ and Vasilis Galis
}

\section{INTRODUCTION}

In 2018, the interdisciplinary research project "DIGINAUTS-migrants' digital practices in/of the European border regime" set off to explore the information practices of migrants and solidarity networks across specific European regions along contemporary migration routes (Greece, Germany, Denmark, and Sweden). Central to this effort was the role of

V. Makrygianni $(\bowtie)$

Copenhagen, Denmark

A. Kamal

Department of Cultural Sciences, Linnaeus University, Växjö, Sweden

e-mail: ahmad.kamal@lnu.se

L. Rossi

IT University of Copenhagen, Copenhagen, Denmark e-mail: lucr@itu.dk

(C) The Author(s) 2022

M. Sandberg et al. (eds.), Research Methodologies and Ethical Challenges in Digital Migration Studies, Approaches to Social Inequality and Difference, https://doi.org/10.1007/978-3-030-81226-3_2 
information and types of communication technology (ICT) in circumventing and challenging the European border regime (see also Sandberg and Rossi in the Introductory chapter of this volume). To address the implicated role of ICT in contemporary migration, the research team applied a mixed-methods approach that would bring together offline ethnographic fieldwork with large-scale online data analysis. While the analytical potential of this approach, and the methodological and epistemic frameworks underlying it, are explored by Sandberg, Mollerup, and Rossi in Chapter 3 of this volume, it is useful to explain the initial context in which the DIGINAUTS project evolved. The idea was to produce a map of the digital resources and spaces that constitute a considerable part of the informational background of contemporary migration. For instance, a Syrian refugee's account of her experiences in Lesvos (Lesbos), Greece, needs to be contextualised within the public content from migrant-oriented pages and websites based in Greece that provide part of the set of informational resources drives the journey. Within this perspective, DIGINAUTS had neither a solely online focus and nor did the project aim complementing the two data sources but at understanding the relationship between online information and offline actions. This is exemplified by the contrapuntal approach, developed and presented in Chapter 3.

In order to make the integration between large-scale digital data and ethnographic observations possible, DIGINAUTS aimed at mapping the space where the digital encounter of migrants and solidarity workers takes place-which we refer to as migrant digital space (MDS). In digital migration studies, such endeavours are rare (Gualda and Rebollo 2016), as most studies of migrants online rely on interview-based studies (Dekker et al. 2018), smaller-scale online studies, or topic- or group-specific largescale data collections (Kok and Rogers 2017). When compared to the wealth of studies on digital diasporas (Laguerre 2010), there are few studies of the digital networks of in-transit migrants; yet even fewer studies are conducted mainly online, see, for instance, the data-orientated research of Kok and Rogers (2017) and Sánchez-Querubín and Rogers (2018). Most scholars investigating migrants' adaptation of digital

\footnotetext{
V. Galis

Center for Digital Welfare, IT University of

Copenhagen, Copenhagen, Denmark

e-mail: vgal@itu.dk
} 
space have relied primarily on first-person interviews (Dekker et al. 2018; Gillespie 2018; Leurs 2014), ethnographies (Grzymala-Kazlowska and Phillimore 2018), or surveys (Merisalo and Jauhiainen 2020), to identify relevant online sites, user preferences, and the benefits afforded.

The DIGINAUTS researchers set out to analyse DMS through publicly available user-generated content before research teams operating independently undertook the main part of the ethnographic work. While the sub-team in charge of the digital data collection researched initially at the various sites (Germany, Greece, and Øresund region encompassing the Danish-Swedish borderlands) to identify valuable seeds (relevant online resources and actors) for the data collection, the tools, and the techniques needed to be established in advance.

In this chapter, we develop an analytical framework for understanding the ways in which migrants and digital spaces are intertwined, and we investigate (digital) spaces that allow for circumventing borders, solidarity practices, and for shaping migration. This materialises into what we define as Migrant Digital Space (MDS). We position MDS within the existing research of migrants and digital technologies, we briefly report on the steps and guidelines we adopted to collect the data, and we present a qualitative overview of MDS, as we have defined it, highlighting some specific characteristics and possibilities.

\section{Migrants' Digital Traces}

The study of migrants' engagement with ICT has long been of acute interest to researchers from various fields, such as migration studies, media and communication studies, critical border studies, anthropology, and science and technology studies (see, for instance, the works of Alencar 2018; Aouragh 2011; Brinkerhoff 2009; Diminescu 2008; Leurs 2014, 2015; Leurs and Smets 2018; Madianou and Miller 2012; Siapera 2014). Recent works (Drüeke et al. 2019; Latonero and Kift 2018, also Gillespie 2018), as well as the special-issue Forced Migrants and Digital Connectivity in Social Media and Society journal (2018) and the volume The Sage Handbook of Media and Migration (Smets et al. 2019) provide a complete overview of the complexity of the issue. Several studies and research projects were developed during the 2015 European migration crisis, and the number of publications on the topic is growing. Research projects such as "WhyWePost" (Miller et al. 2016), "CONNECTINGEUROPE: Digital Crossings in Europe: Gender, Diaspora and 
Belonging" (Ponzanesi 2016), "Resilient Communities, Resilient Cities? Digital makings of the city of refuge" (Georgiou 2013) as well as the DIGINAUTS research project have highlighted the impact of ICT on the everyday life of migrants.

This impressive quantity of work covers many different directions of the possible relation between migrant populations and ICT and has evolved considerably over the years to account for new dynamics, new technologies, and new concerns. Rather than offering a complete overview of the whole field of research, in the following we organise some of the existing research based on how these recent contributions approached the idea of migrant space within digital migration studies and how that has affected how MDS was developed within DIGINAUTS.

ICT has often been studied in the guise of tools able to provide access to valuable informational resources. The nature of these resources as well as "when" the resources are thought to be used in the migration processes varies considerably: researchers (Dekker et al. 2018) highlighted the role of ICT in providing access to valuable information before the journey, while others (Alencar 2019) have shown how migrants who are already settled in the country of destination, as well as solidarians, adopt various kinds of ICT to offer sought-after resources leading to the emergence of "transglocalised" networks (Kok and Rogers 2017). As they argue, the particular territorial arrangement and engagement of the digital are what form a transglocalised network where local networked formations exist alongside national and transnational formations, each operating with awareness of the other yet acting separately.

As our case study shows, the thematic of online activity vary and depend on the different means, the distinct digital subjects, and the various geolocations. For instance, while in many cases researchers have focussed on practical information both to reach the country of destination as well as to facilitate a resettlement process, ICT can also provide migrants with valuable social and emotional capital (Marino 2015). Also, it is notable how practices of care develop in the digital sphere (Leurs 2019; Alinejad and Ponzanesi 2020) among individuals and communities and produce digital spaces of care (Makrygianni and Galis, forthcoming). In this context, it is interesting to observe how, while ICT is generally described in terms of potential access to information, there is a parallel interest focussing on how trust in specific information is constructed (Dekker et al. 2018; Mollerup and Sandberg, forthcoming). As Gillespie et al. (2016) explain, there is a paradox between the growth of available 
information and the lack of timely, relevant, and reliable information that makes the migrants' decision of which informational resource should be trusted more complex.

This growing body of research depicts the social, digital, and physical space where the migration process takes place as extremely complex, populated by various actors and supported by different types of "infrastructures" (Dekker et al. 2018). Media and communication studies have shown how migrants create digital spaces of homemaking, and becoming (Georgiou 2013; Leurs 2015; Madianou and Miller 2012; Witteborn 2014; Xie and Witteborn 2019). Smets (2018) discusses the idea of "mobile homes" and Almenara-Niebla (2020) the "digital home-camps" to expand the field of research beyond media studies. Latonero and Kift (2018) bring the notion of "digital passages" to grasp both the temporal condition and the architectural constraints of the migrants' movement within this space. Similarly, Gillespie et al. (2018) draw on the work of Smets (2018) and Roseneau (2003) to discuss the concepts of "digital passages" and "distant proximities" while Leurs (2015) also builds on the passage in order to address issues of navigation in digital space. In addition, research on place-making practices that relate to digital activities has started gaining ground (Bork-Hüffer 2016; Lim et al. 2016; Polson 2015; Witteborn 2012, 2015). Recently, Smets et al. (2019) have addressed issues of space in a chapter of the already highlighted volume The Sage Handbook of Media and Migration dedicated to the spatial dimension. There, most of the authors (Alencar; Alevizou; Costa and Wang; Xi and Witteborn) elaborate on a more relational approach to space and pay special attention to reterritorialising processes and place-making practices.

These various ways of defining the space where migration takes place are often quite diverse in terms of the actors that "populate" and produce this space, in terms of the size of the space itself and in terms of the challenges that it poses. We claim that some aspects of this diversity can be explained by looking at the various methods used to "map" the space. After all, both the data we collect about any space as well as the research methods and processes (related, for instance, to different scales or timelines) will, unavoidably, define our conceptualisations and representations of it.

Within this perspective, we chose to adopt a data-centric lens to organise the existing research. Data-centric means that we organised the 
existing research about migrants and refugees according to their datacollection strategies: ethnographic approaches, selected groups of sources, and large-scale data collections.

Research with a strong qualitative orientation, usually conducted either through multi-sited ethnography (Charmarkeh 2013) or in-depth interviews with selected subjects (Dekker et al. 2018), defines the migrant space both through the specific migrant population and the specific actors they include in their research design. The size and breadth are defined by the phenomenological nature of both the analysis and, mostly, the datacollection practices. Within this approach, the definition of the borders of the migrant space is determined by the actual experiences of the subject, either directly reported or mediated through the ethnographic practice or the researcher.

An alternative approach involves research aimed at mapping the digital experience within a specific geographical context (Kaun and Uldam 2018) or within a specific type of actor (Dessewffy and Nagy 2016). In this case, the actors are usually pre-selected and then their digital activity is tracked or monitored. The size and breadth of the space are defined by the set of actors that are included in it. To limit the possible problem deriving from this approach, the set of actors that are studied can be obtained or complemented with computational methods based on crawling of digital resources (Kok and Rogers 2017).

A third approach is what can be defined as large-scale data collection. In this case, actors are usually identified using the affordances of a preexisting digital platform or social media service. This could have different practical implementation depending on the digital data the research is actually working with: it could be searching for specific keywords on Facebook or following specific hashtags on Instagram or twitter. For example, Siapera and colleagues $(2018)$ used a set of "refugee-related" hashtags to identify a data set of 7,500,000 tweets. In this way, they were able to represent a discussion space that is largely co-opted by mainstream entities (politicians, media, NGOs) and frames (humanitarian vs. far right) and would probably be invisible through an alternative type of data collection.

Those three strategies have different scopes, goals, and ambitions. While this diversity is largely a natural consequence of the variety of research methods and preferred data, we claim that a careful design of a mixed-methods approach allows for constant alterations of the scale of the research that minimises the unavoidable blind-spots of digital data collection. Therefore we suggest both a macroscopic level of analysis-a 
"birds-eye view" of the data-as well as a smaller-scale in-depth overview of the (digital) everyday practices of the digital subjects.

\section{Configuring Migrant Digital Space}

This section problematises and conceptualises migrant digital space that is configured by migrants' online activity before the journey, en route, and when settling. By conceptualising MDS as a space shaped by practices, we aim to (a) understand the various digital-place-making practices, (b) investigate the relation between human mobility and digital, and (c) map migrants' spatial footprints in the digital sphere. We follow a relational approach to space (Lefebvre 1991; Massey 2005; Harvey 2006), according to which, space is not considered as a life container but as a derivative of social relations and interactions. Therefore, we understand MDS as an outcome of social relations and practices with material and intangible characteristics.

With the concept of MDS, we conceptualise an online (and offline) arena where information, knowledge, communication, advocacy, and representation of migrants is enacted by leveraging contemporary digital technologies. This space is formed by (a) digital subjects (accounts, pages, hashtags, channels) touching on (b) migrant-related topics (such as discussions on migration routes; language lessons; football conversations; university enrolment; job seeking) through conversations across (c) various digital platforms. MDS is thus first defined by this triple multiplicity: multiple actors, multiple topics, and multiple platforms. While previous studies have positioned physical spaces as either "a binary or an opposition to the perceived virtuality of the emerging web" (see Shah 2019), in our approach, we highlight the interconnection and interdependence of analogue and digital spatialities. Migrants' online activities are formed from a simultaneous use of software (which requires time and communication skills) and hardware, i.e., devices, antennas, cables, and satellites. Moreover, MDS represents simultaneously a counterpoint to and an extension of migrants' everyday life in physical spaces (camps, borders, city centres, streets, plazas, parks, routes, trains, neighbourhoods, libraries, cafés, etc.) where they enact their agency and constraints, whether with respect to mobility, information seeking, social interactions, or entertainment, and so forth. Thus, MDS is synthesised by internetbased platforms, digital subjects, and elements of physical/material space. 
In terms of form and function, MDS is a space for commoning that incorporates characteristics of a public space such as diversity, heterogeneity, and contradictions. Information sharing, facilitating access to goods and infrastructures and various solidarity acts thrive beyond commodification practices and constitute MDS as a space of commons rather than a space of commodities (An Architektur 2010). While we describe MDS as a space for commoning, it should be noted that the very same digital space spans several contradicting dynamics taking place: access to the MDS raises questions about the accessibility of the digital space (Khorshed and Imran 2015,344 ), which emphasises pre-existing inequalities, as well as a growing issue of trust in the actors and content populating the digital space (Borkert et al. 2018, 1; Gillespie et al. 2018, 1). Within the new context, the individual ability to navigate these uncertainties as well as the technological divide that accompanies it become the main elements that define membership of the space rather than race, ethnicity, gender, or physical space characteristics and biases. Primarily, it is a space that enables encounters and conflicts among analogue and digital subjects. As this space for practices emerges from subjects, topics, and platforms and has a clear connection with the physical and material space, it should appear clear that we can hardly imagine dealing with a single, unique, MDS. On the contrary, we need to embrace the idea that MDS has a spatial dimension that necessarily results in multiple, partially overlapping, Migrant Digital Spaces since subjects, topics, and platforms combine differently for the different geographical contexts. The network of relevant resources, topics, and actors will, while partially overlapping for the European border regime, also varies due to local specificities.

The digital resources we have identified would thus carry relevant information differentiated according to different temporalities and geolocations. For example, as we will show more analytically further on in our data sets, the pages with a geolocation in Greece focus mainly on primary needs, in Germany on information on settling down, in Sweden on asylum seeking, and in Denmark on spaces for encounters and networking. These needs and topics differentiate especially during periods of crisis, such as the extreme weather conditions of winter 2015 in Greece (which we designate the "winterisation" period).

\section{The Practice of Mapping MDS}

As mapping an unknown space presents a series of methodological challenges, we had to employ a set of navigation tools. Based on the 
conceptual description outlined in the previous paragraph, we considered the migrant digital space as an unknowable and unstable set of digital resources available to migrants before, during, and after their journeys. We considered it unknowable because it is defined by an unknown number of entities that are, in many cases, hard to identify in a binary distinction between relevant and non-relevant entities. As soon as we move beyond the official organisations or larger NGOs, the digital space offering resources for migrants is characterised by small entities, often with an unclear status, which may highlight the specific issue only for a limited time period (e.g., in the midst of large humanitarian crises). We decided to adopt a migrant-centric perspective when defining what could constitute a "useful resource". This means that the criteria for a resource to be included in our mapping activity was its ability to provide information that could have been valued as relevant by the migrant population, rather than using any top-down criteria of relevance or authority. We soon realised that often the relevant information found in a large variety of digital spaces: from the above-mentioned digital presence of large solidarity organisations to small (often tiny) groups of solidarians or migrants - already living in one of the destination countries-is provided by people who, at a particular moment in time, decided to step up and help. These heterogeneous resources are clearly scattered across the digital world on various platforms: from Facebook to websites, from WhatsApp groups to telegram channels. Each digital platform is clearly accompanied by its own set of technical affordances and user expectations. Moreover, as a consequence of the wide-ranging actors and motivations, the migrant digital space is also unstable. The abundance of minor and informal actors that, thanks to the opportunities offered by contemporary social media platforms, entered the digital space to provide relevant information for migrants also produced high instability in the space. Mapping, within an unstable digital environment, has a very clear-and often shorttemporal dimension, it is an act of representation of spacetime. Online spaces are often created and become inactive (or are left abandoned) within months, information becomes old and outdated, and the general space is constantly reshaped. This instability lies behind what Gillespie and colleagues (2018) describe as a "Paradox": a growth in available information that corresponds to a growth in uncertainty due to the inadequacy or unsustainable nature of this information. Thus, mapping is an incomplete process that exposes the incoherence and fragmentations of migrants' digital spatialities. As a research practice, it is not a taxonomy or an 
ordering process of migrants' everyday digital practices but an incomplete action, "a simultaneity of unfinished stories", as Massey (2003) describes space itself.

Given these premises, the effort to map the Migrant Digital Space had to be anchored to four axes of research:

(a) A user-centric perspective

When selecting the actors that would populate the migrants' digital space, we decided to focus on migrants looking for information. We did that using a combination of keywords from specific searches both in the local languages (German, Greek, Danish, and Swedish) as well as in community languages (Arabic) and English to identify valuable online resources. We complemented those with pre-existing information that we identified in 12 pilot interviews conducted in Greece during the summer of 2016. Moreover, along with the online data gathering (spring 2018) we initiated our qualitative research and located four informants in the Øresund region (Copenhagen), six informants in Germany (Hamburg), and three in Greece (Athens) (all interviewees were migrants who arrived in Europe in about 2015). We asked them to guide us in their digital spaces and paths while suggesting the most and less popular and trustworthy pages. Locating our digital actors and our interviewees was a result of online and offline snowballing.

(b) Ethical data collection

From the very beginning of the project, we decided that we would work only with publicly available data. This led to the exclusion not only of private mobile data (e.g., WhatsApp group conversations) but also of data that could have been perceived as private but that could have been accessible for research purposes (e.g., closed Facebook groups). While we adopted a migrantcentric perspective for snowballing sources, we opted for removing any identifiable information on the migrants from our data even when this meant being unable to trace the information-seeking activity of individual migrants. While we recognise that Facebook, as well as other platforms, ( 1 ) is centralised and the flow of information is vastly controlled and biased (see, for example, van Dijck 2009; Ho 2020), and (2) does not always secure a safe space for all (see, for example, cyber hate cases), the simultaneous presence and interaction of millions of people, regardless of the existing 
contradictions, suggest that it is perceived, at least partially, as a possible space for debate. We argue that such spaces constitute spaces of othering, spaces of healing, care, and emancipation for the migratory populations.

(c) Temporarily limited

As mentioned before, MDS is characterised by its ever-changing nature. While hypothesising that ongoing data collection is undoubtedly fascinating, practical reasons, as well as the restriction imposed by Facebook on data access (Bruns 2019), forced us to define a firm end for the data collection $(24 / 09 / 2018)$. While the option of collecting past data gave us the opportunity to collect longitudinal data, the data should still be approached as inherently unstable since an unknown quantity of data could have already been deleted from the platform previous to our data collection.

(d) Alteration of scales

The mixed-method approach led us to simultaneously conduct research on various scales to conceptualise and represent MDS. Thus, we considered testimonies of individuals (that suggested popular pages according to personal criteria) as well as snowballing our online research to come up with our data set. As feminist scholars note (Massey 2005; Smith 1987; Yuval Davis 2007), the alteration of scales (which entails more of a qualitative than a quantitative differentiation) examines practices at a macroscopic level and on a molecular basis and deconstructs the (digital) common sense. By focussing on migrants' everyday digital practices, we shed light on the various cultural geopolitical and social inequalities embedded by bordering practices. As we will show further on, the alteration of scales is a constant revisiting of migrant's everyday practices that reveals minor scale tactics of resistance against major scale institutional strategies of repression. Brenner $(2001,608)$ indicates that "the establishment and reorganization of scalar hierarchies creates geographies and choreographies of inclusion/exclusion and domination/subordination which empower some actors, alliances and organizations at the expense of others, according to criteria such as class, gender, race/ethnicity and nationality".

In our case, migrants' minor digital acts deconstruct hegemonic (institutional) narratives that reproduce the nation-state rationale and uncover 
places of discipline and power that spread from migrant's bodies to transnational territories. For instance, focussing on data coming from (less populated/less popular) LGBTQ+ pages (following a suggestion from some of our LGBTQ+ interviewees) revealed a spectrum of large-scale institutional bordering practices imposed on migrant's bodies due to their gender or sexual orientation.

The combination of these guidelines led to the definition of the data set we used to describe the MDS. On a practical level, constructing the digital data set developed according to the following three steps:

1. The research team identified an initial set of digital resources (448 public Facebook pages) that fulfilled the above-detailed criteria and corresponded to the specific geographical focus of the project.

2 . The research team manually coded each page according to a set of criteria of interest for the research project. These were: the full names of the page, the main language used on the page, the geographical area of interest of the page (e.g., a German page could support search and rescue operations in the Aegean sea), the country of the organisation behind the page, the organisational level of the organisation behind the page (institutional, semi-institutional, non-institutional), and if the page focussed on LGBTQI issues.

3. Using the-now defunct-public Facebook API, we collected all the content publicly available on the pages from the creation of the page until the date of the data collection (September 2018). Given the shutdown of the Facebook API during the data collection, not all public pages that were initially identified (448) have actually been fully collected.

The final data set was composed of 200 Facebook pages that were then manually coded with additional information such as the type of actor behind each Facebook page, the physical location of the actor, the date when the page was created as well as the language (or languages) used. At the same time, all the content (posts, comments, and reactions) publicly available on the pages was downloaded using Facebook's API. This produced a final data set totalling 200 pages, 84,359 posts, and 2,254,923 comments, produced between 20/12/2010 and $24 / 09 / 2018$. 
In the following sections we show how the data collected in the MDS can be used to investigate the intersection of digital resources with migrants' everyday lives. This should not be understood as an in-depth analysis of the issue but more as a demonstration of the research that the mapping of the MDS makes possible. It should be acknowledged that this research can also be investigated with different data or strategies but, we claim, a throughout mapping of the relevant migrant digital space provides several benefits either because of the types of actors that can be included in the research, because of the longer longitudinal perspective that can be adopted, or because of a facilitate comparative perspective.

\section{Migrants’ Everyday Digital Places}

There is a strong interdependence between migrants' everyday practices and digital space. Following the discussions on the notion of place that is formed by peoples' lived experiences (Massey 2005), digital places derive from the everyday life experiences and practices of migrants. Along the same line, thinkers from the field of feminist studies, sciences of space and social sciences (Smith 1987; Lefebvre 1977/2014; de Certeau 1980/2013; Massey 1994, 2005) have pinpointed the importance of everyday life in the (trans)formation of space. De Certeau in "Practices of everyday life" 1980/2013 investigated "routine practices", such as walking, talking, reading, and cooking, and he found creative resistance to these "arts of doing" of ordinary people. In a similar way, migrants, as minor actors (Margetts et al. 2016), perform various digital practices (digital arts of doing) such as group chats, video calls, microblogs, emails, online games, online music, and online shopping, posting, commenting on social media, sharing, (dis)liking, microblogging, and so on. Such digital arts of doing reveal a plurality of themes, relevant actors, and digital spaces that create migrants' digital places. While migrants' everyday lives take place both in physical and digital locations, several of their primal needs are fulfilled when forming their digital spaces of commoning. Their digital routine practices develop mainly around information sharing on the migration status and on the journey.

If we start looking for these everyday dimensions in the data set we collected, we can observe how the MDS is filled by a multiplicity of everyday problems and challenges that migrants address through digitally enabled commoning. However, we recognise that since we never laid eyes on private groups and certain platforms (due to ethical restrictions), there 
are limitations in our understanding of the notion of everyday in digital space. Among the many possible examples, we will briefly hint at a few that stood out in our reading of the data and constitute potential avenues for further analysis in digital migration studies.

\section{The Evolution of Everyday Life Throughout the Journey}

Figure 2.1 shows how most of the 64 non-institutional entries located in (various places in) Greece involved the distribution of food (e.g., No Border Kitchen). Fifteen pages developed around news and information about travelling and raised awareness of migrant issues (with one specifically aimed at "provid[ing] help and support from around the world with phone top-ups for refugees and displaced people". Another fairly common feature were pages with information on legal issues, pages about housing collectives (such as the "City Plaza", or the "Notara housing project"), education services (page of the "NO BORDER school"), and a page to support and raise money for medicines, food, water, etc. Less common were pages directly addressing LGBTQ+ solidarity or job

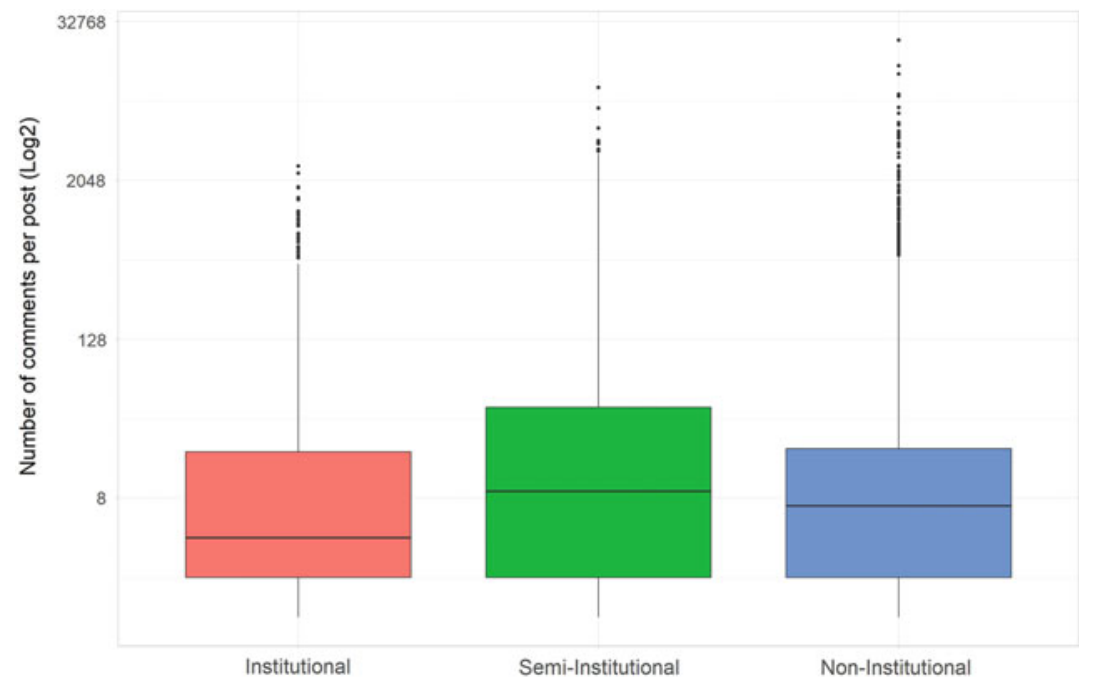

Fig. 2.1 Types of actors. This image is used with permission of the authors of this chapter [Rightsholders] 
seeking (the page "Work opportunities for refugees in Greece" proudly proclaimed to be "the only one in Greece with this thematic").

The issues at the centre of the Facebook page activity change as we focus our attention on different geographical contexts.

Of the 125 pages located in Germany, two relate to LGBTQ+ solidarity, while the vast majority are about sharing information on refugee issues. We also found a page that acted as a Hamburg city guide (Yalla: "We give you tips for Hamburg. We discover places, activities and groups in our city"), and another offered "assistance for reunification" (Assistance for Syrians reuniting their families). Of the 83 pages located in Sweden, most involved information on asylum processes and one was specifically orientated towards LGBTQ+, once again providing information on asylum processes. Of the 40 entries in Denmark, most concerned networking and information on everyday life. One page was dedicated to practical issues (\# HjelpEnFlygtning, which, as they mention, "is the place where you can offer refugees a home, a job/an internship, language teaching, friendship/networking, or leisure activities"), another offered legal advice (Jurarådgivning), and one was for LGBTQ+ asylum seekers (LGBTQ+ ASYLUM).

\section{Everyday Vulnerability}

Scholars such as Shah (2019) stressed the relation between the digital place forming practices with the critical discourse on vulnerability and the agency of bodies in the face of accelerated digitisation. Our data set contains various entries that involve the so-called "vulnerable subjects". According to some of our informants (involved with the "Lesvos Lgbtiq+ Refugee Solidarity" page), such pages act as empowerment tools, as they open the discussion on vulnerability and provide affect and compassion and sometimes alternatives. As mentioned above, we traced some LGBTQ+ solidarity groups in all three geolocations. In particular, in Greece we found three related pages: "Lesvos Lgbtiq+ Refugee Solidarity", "Lgbtqi+ Refugees" in Greece and "Eclipse". From previous field research, we found that these pages also generated physical meetings among the group members and various offline events of solidarity in analogue space. We also located one page from Germany dedicated to issues of bodily ability ("The National Association of the Deaf North Rhine-Westphalia, which 'supports deaf refugees from their arrival until they have settled in"'). Another German page was dedicated to parenting 
and guardianship (named "AKINDA", it "supports young refugees and minors who arrived in Berlin without parents").

\section{Non-institutional Is More Trustworthy?}

As mentioned in our mapping practices, we grouped the digital actors of our initial set of identified pages according to their institutional or non-institutional affiliation (of 448 entries, 317 are listed as noninstitutional-see Fig. 2.1). This differentiation (between institutional, semi-, or non-institutional) highlights the different standpoints of the actors behind the pages and reveals the power geometries (Massey 1999) of migrant digital space. Such hierarchical division of the data can be used to make visible different strategies and tactics on behalf of the various actors in this spatial battle of "repression and expression" (De Certeau 1984). While potentially enacted also by "ordinary people", strategies are associated with hegemonic regulations and disciplinary mechanisms. In a migration framework, such regulations and mechanisms are to control both transnational mobility as well as the materialities of everydayness in migrants' settlements. Tactics, on the other hand, derive from daily practices of "ordinary people" that are not implied in certain institutional borders. As pointed out by De Certeau (1984, 117) and Yilmaz (2013, 68), these tactics are performed by those who are not included in the power group creating the power apparatus, such as workers, migrants, and subaltern ethnic minorities and tend to erode power mechanisms. Such digital tactics lack a permanent position and evoke distortions of (institutional) strategies of power, such as bordering and racialised practices. Applying this distinction to the data we collected, it means to understand how and if the institutional actors were providing informational resources aligned with the hegemonic regulations and if, on the opposite side, non-institutional actors were offering what we could define as tactical information.

When analysing our data set, we observed the differences between state and institutional strategies and the migrants' tactics on both the online and offline battlegrounds. Simply looking at the average number of comments received by the posts on the various types of pages shows how institutional pages, while having the largest numbers of followers, receive a smaller number of comments. From our field research, we know that mistrust in institutions led to augmented digital activity of non-institutional actors. Although "system avoidance" (Latonero and Kift 2018 ) is a practice of defence, the minor actors of our data set eventually 
took control of their own environment and restored a sense of identity, attachment, and belonging to their places of reference (whether these are spaces formed for shorter or longer periods). For instance, information regarding legal advice was circulated mainly by non-institutional actors (such as the Danish page for free legal advice, "Jurarådgivning" formed by law students at the University of Copenhagen), or the various pages in the German and Swedish digital spheres that come from the non-institutional listing and involve information for asylum seekers. Such processes of digital place-making that generate places of trust involve "processes of participation which include a conception of civic agency and the conditioning of space - affective, material, social, mediated" as Alevizou (2019) points out. These tactics of non-institutional actors seeking trustworthy online places differ according to geolocation. For instance, in the Greek case, it seems a large number of pages related to primal needs (such as housing and food) emerged especially around the year of 2015. Drawing from the data set but also from our informants' testimonies, the popularity of such non-institutional pages is not only due to mistrust towards the state authorities but also resulted from the state's failure to cover migrants' basic needs during the long summer of migration (2015).

\section{Temporal Evolution of MDS}

A final note on the challenges and possibilities of this time of approach to data collection should focus on the issue of temporal evolution of digital data. As noted above, MDS is understood as a time-sensitive entity, given the rapidly changing international and domestic context and the instability of the user population. The ephemerality of digital subjects within MDS is also a consequence of the unstable conditions faced by many of its actors and participants. For instance, in our case, this temporality was evident during the four months since between the two rounds of data collection (June and September 2018), already approximately $5 \%$ of the accounts had been discontinued. In addition, the acceleration of online information sharing fosters a compressed space that breaks traditional barriers. In this sense, we are witnessing the construction of various spatio-temporalities within the digital realm. Considering the different events during the migration crisis, we noticed very different temporal dynamics, depending on if the pages were of institutional, semi-institutional, or non-institutional actors. While very few institutional 
pages became active during the time covered by our data collection, we observed a sharp rise in non-institutional pages created between 2014 and 2017. This period included: (1) The "long summer of migration", which refers to the increase in migrants arriving in Europe during the summer of 2015, (2) The enactment of the EU-Turkey deal in March 2016, which resulted in around 50,000 migrants being "trapped" on Greek territory for several months, and (3) The so-called "winterisation period" (a term introduced by international NGOs referring to harsh weather conditions that exacerbated the suffering of thousands migrants in that region of Greece (see UNHCR 2015; Papataxiarchis 2016). During this period, many primal needs of migrants in Greece were fulfilled not by institutional actors but by non-institutional volunteers and activists. At this stage, several online and offline networks were activated as a reflexive response to the multiple crises. It is interesting to observe how the activity on semi-institutional pages peaked later than the non-institutional pages, suggesting that informal groups with little or no formal structure reacted quicker online to offline events than their formal counterparts.

However porous and unstable it may seem, MDS still facilitates analogue place attachments. Digital technologies reterritorialise specific activities and engagements. Brun describes the reterritorialising process of as "the way in which displaced people and local people establish new, or rather expand networks and cultural practices that define new spaces for daily life" $(2001,23)$. Within this context, migrants are articulating connections to various places and various actors at various moments in time. This makes MDS a temporarily stable space, kept in existence by the engagement and reterritorialising activity of its actors.

\section{CONCLUSIONS}

The overall methodological goal of the DIGINAUTS project was to apply a mixed-methods approach to bringing together offline ethnographic fieldwork with large-scale online data analysis of in-transit migrants, a rare endeavour in the literature. This was not merely for reaching analytical complementarity in mixing big and thick data sources (Bornakke and Due 2018). We aimed for a hybrid space where everyday experiences are entangled with a large pool of digital data, traces, information, and so on. We coined the concept of Migrant Digital Space to conceptualise this hybrid and contrapuntal space. Besides the ontological synergies between ethnographic and digital data, the DIGINAUTS research methodologically 
constructed this space by selecting publicly available online user-generated content, which also acted as an inspirational point of departure for the launch of the ethnographic work (Mollerup and Sandberg, forthcoming). While we acknowledge the constructed nature of this space, we have also shown how it can function as a curated map, producing a partial but relevant representation of the digital actors, which resonates with the offline events. Previous impressive research on migration and digital media has addressed the multiplicity that characterises the use of ICT by migrants before their journeys, en route, and while settling down. This work has diversely described and defined different spaces populated by migratory subjects. This chapter suggests that spatial diversity is also enacted through the methodological multiplicity used to represent space. In onto-epistemological terms, the research methodology for selecting data as well as the data themselves enact the conceptual representation of space.

In our research and methodological context, migrant digital space opens the possibility of a combination of a macroscopic level of analysis and a more small-scale in-depth overview of the (digital) everyday encounters of migrants with digital media. By focussing on longitudinal temporal evolutions (e.g., Fig. 2.2) we observe macro trends and the impact of world-events on digital data, while, at the same time, we can dive into a user-centric perspective by analysing single messages or single pages. Following a relational approach to space, MDS constitutes an online-offline polyphony that implies flows of information, knowledge, advocacy, solidarity, politics, as well as hazards between and for migrants. This multi-layered space consists of digital subjects, migrationrelated topics, and several different digital objects. These multiple layers simultaneously define and enact MDS. At the same time, given that we linked digital space with specific geolocations (Greece, Germany, and the Øresund region) and temporalities (specific critical moments in contemporary genealogy of migration to Europe), these dimensions also define MDS. In other words, MDS is sensitive to geographical and temporal properties. Therefore, the practice of mapping the MDS reflects that a space at the intersection of the offline-online worlds is simultaneous and polyphonous. This is not a binary but a multi-levelled space. Mapping is not performed as a "technology of power" but as an unfinished practice, an arena of possibilities that disrupt the sense of coherence and of totality (Massey 2005, 109, 120). With that said, we also acknowledge the complexity of this methodological endeavour. Moving beyond 


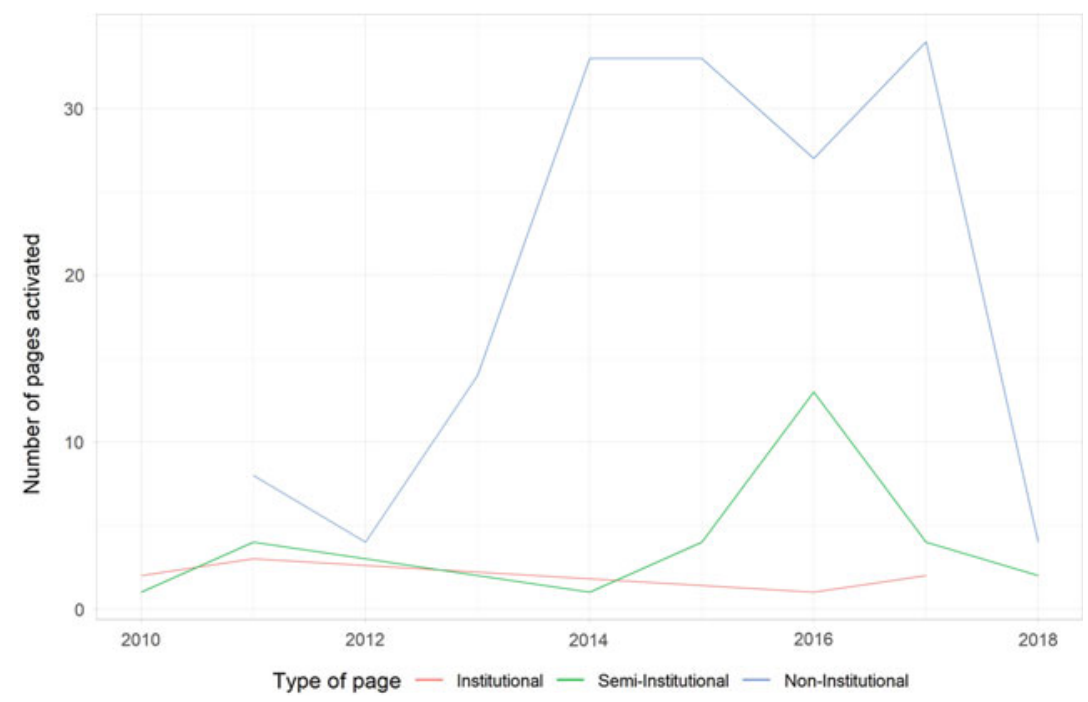

Fig. 2.2 The ephemerality of MDS defines a porous spatiality always under construction where accounts and pages are abandoned and created continuously while new applications enter the arena. This image is used with permission of the authors of this chapter [Rightsholders]

established methodological as well as empirical space brought us to unexplored waters in the sense that we did not limit our research to the official digital voices of formal institutions or actors involved in migration politics. Exploring the MDS also involved taking into account methodological and empirical heterogeneous resources spread across the digital sphere and various digital platforms: commercial social media, websites, and messaging and voice-over-IP services, among others. While not all these sources ended up being "collected data", for the ethical reasons discussed above, they still constitute data that the researchers can, with a range of ethically robust strategies and non-computational methods, integrate within the research. This meant the constitution of the MDS was rather unstable as the digital traces and switches between different media are entirely random and unruly, while the survival of digital subjects was also unpredictable. The MDS evolves in a constant and dynamic state of reshaping. 
We therefore suggest four axes for working with MDS: (A) Usercentric perspective. This is also compatible with an Autonomy of Migration perspective, meaning that we compose MDS with migrants' digitally expressed interests as a point of departure. (B) Ethical data collection. We show epistemological solidarity with migrants by protecting and respecting their digital privacy as well as potentially controversial information retrieved online that exposes them and their mobility to risk. (C) Temporarily limited. As we saw, accessing data is one thing. Accessing for a longer period is quite another. Even when large online platforms, such as Facebook, make data available, researchers have no guarantee that the data they retrieve is accurate or long-lasting. (D) Alternation of scales. The multifarity of MDS allows us to apply digital methods on several scales, challenging digital commonsensical patterns.

An important element of MDS worth discussing separately here is migrants' everyday digital practices, since they provided us with significant classifications of everyday life practices that were directly projected in digital space. Group chatting, video calling, microblogging, emailing, online games, online music, online shopping, posting, commenting on social media, sharing, (dis)liking, and so on populate an MDS much larger than our data collection would suggest and possibly larger than any future version of the concept. Migrants, in this expanded MDS enact themes, problems, and challenges that they face and confront daily. Some of it trickled down into the public, ethically acceptable, Facebookcentric version of the MDS that we defined, and this enabled us to reconstruct and analyse migrants' everyday life throughout their journeys. Issues related to food distribution, sexuality, job seeking, navigation, legal advice, education, housing, and economic solidarity were themes directly apparent in our material. This also allowed us to interrelate themes with the specific geographical areas under investigation. The content of the everyday lives of migrants, viewed through the lens of the MDS, altered in the different countries under investigation. As we mentioned above, temporality was also an important factor in the constitution of the MDS. Ephemerality of digital subjects, critical events in the period under investigation (such as the long summer of migration and winterisation), differentiated accessibility and availability of data in time depending on digital platforms' policy strategies, and the nature of digital subjects (institutional, semi-institutional, and non-institutional) significantly reshaped the MDS. 


\section{BIBLIOGRAPHY}

Alam, Khorshed, and Sophia Imran. 2015. "The Digital Divide and Social Inclusion among Refugee Migrants: A Case in Regional Australia." Information Technology \& People 28.

Alencar, Amanda. 2018. "Refugee Integration and Social Media: A Local and Experiential Perspective." Information, Communication and Society 21 (11): $1588-1603$.

Alencar, Amanda. 2019. "Digital Place-Making Practices and Daily Struggles of Venezuelan (Forced) Migrants in Brazil." In The Sage Handbook of Media and Migration, edited by K. Smets, K. Leurs, M. Georgiou, S. Witteborn, and R. Gajjala, 503-513. Thousand Oaks, CA: Sage.

Alevizou, Giota. 2019. "Civic Media and Placemaking: (Re)Claiming Urban and Migrant Rights Across Digital and Physical Spaces.” In The Sage Handbook of Media and Migration, edited by K. Smets, K. Leurs, M. Georgiou, S. Witteborn, and R. Gajjala, 489-502. Thousand Oaks, CA: Sage.

Alinejad, Donya, and Sandra Ponzanesi. 2020. "Migrancy and Digital Mediations of Emotion." International Journal of Cultural Studies 23 (5): 621-638.

Almenara-Niebla, Silvia. 2020. "Making Digital 'Home-Camps': Mediating Emotions among the Sahrawi Refugee." International Journal of Cultural Studies 23 (5): 728-744.

Amelina, Anna, Horvath Kenneth, and Meeus Bruno, eds. 2016. An Anthology of Migration and Social Transformation: European Perspectives. Cham: Springer.

An Architektur. 2010. "On the Commons: A Public Interview, with Massimo De Angelis and Stavros Stavrides." e-flux (17).

Aouragh, Miriyam. 2011. Palestine Online: Transnationalism, the Internet and the Construction of Identity. London: Tauris.

Bork-Hüffer, Tabea. 2016. "Mediated Sense of Place: Effects of Mediation and Mobility on the Place Perception of German Professionals in Singapore." New Media and Society 18 (10): 2155-2170.

Borkert, Maren, Karen E. Fisher, and Eiad Yafi. 2018. "The Best, the Worst, and the Hardest to Find: How People, Mobiles, and Social Media Connect Migrants In(to) Europe." Social Media + Society 4 (1): 205630511876442.

Bornakke, Tobias, and Brian L. Due. 2018. "Big-Thick Blending: A Method for Mixing Analytical Insights from Big and Thick Data Sources." Big Data and Society 5 (1): 2053951718765026.

Brenner, Neil. 2001. "The Limits to Scale? Methodological Reflections on Scalar Structuration." Progress in Human Geography 25 (4): 591-614.

Brinkerhoff, Jennifer M. 2009. Digital Diasporas: Identity and Transnational Engagement. Cambridge; New York: Cambridge University Press.

Brun, Cathrine. 2001. "Reterritorilizing the Relationship between People and Place in Refugee Studies." Geografiska Annaler: Series B. Human Geography 83 (1): 15-25. 
Bruns, Axel. 2019. "After the 'APIcalypse': Social Media Platforms and Their Fight Against Critical Scholarly Research." Information, Communication and Society 22 (11): 1544-1566.

Certeau, Michel de. 1984. The Practice of Everyday Life. Berkeley, California: University of California Press.

Charmarkeh, Houssein. 2013. "Social Media Usage, Tahriib (Migration), and Settlement among Somali Refugees in France." Refuge: Canada's Journal on Refugees 29 (1): 43-52.

Costa, Elizabetta, and Xinyuang Wang. 2019. "Being at Home on Social Media: Online Place-Making among the Kurds in Turkey and Rural Migrants in China." In The Sage Handbook of Media and Migration, edited by K. Smets, K. Leurs, M. Georgiou, S. Witteborn, and R. Gajjala, 515-525. Thousand Oaks, CA: Sage.

de Certeau, Michel. 2013. The Practice of Everyday Life. 1: ... 2. Print. Berkeley, CA: University of California Press.

Dekker, Rianne, Godfried Engbersen, Jeanine Klaver, and Hanna Vonk. 2018. "Smart Refugees: How Syrian Asylum Migrants Use Social Media Information in Migration Decision-Making." Social Media + Society 4 (1): 205630511876443.

Dessewffy, Tibor, and Zsofia Nagy. 2016. "Born in Facebook: The Refugee Crisis and Grassroots Connective Action in Hungary." International Journal of Communication IJOC: 2872-2894.

Diminescu, Diana. 2008. "The Connected Migrant: An Epistemological Manifesto." Social Science Information 47 (4): 565-579.

Drüeke, Ricarda, Elisabeth Klaus, and Anita Moser. 2019. "Spaces of Identity in the Context of Media Images and Artistic Representations of Refugees and Migration in Austria." European Journal of Cultural Studies 1367549419886044.

Farman, Jason. 2021. Mobile Interface Theory: Embodied Space and Locative Media.

Georgiou, Myria. 2013. Media and the City: Cosmopolitanism and Difference. 1. publ. Cambridge: Polity Press.

Gillespie, Marie et al. 2016. Mapping Refugee Media Journeys: Smartphones and Social Media Networks.

Gillespie, Marie, Souad Osseiran, and Margie Cheesman. 2018. "Syrian Refugees and the Digital Passage to Europe: Smartphone Infrastructures and Affordances." Social Media + Society 4 (1): 2056305118764440.

Grzymala-Kazlowska, Alexandra, and Jenny Phillimore. 2018. "Introduction: Rethinking Integration. New Perspectives on Adaptation and Settlement in the Era of Super-Diversity." Journal of Ethnic and Migration Studies 44 (2): 179-196. https://doi.org/10.1080/1369183X.2017.1341706. 
Gualda, Estrella, and Carolina Rebollo. 2016. "The Refugee Crisis on Twitter: A Diversity of Discourses at a European Crossroads." Journal of Spatial and Organizational Dynamics 4 (3): 199-212.

Harvey, David. 2006. "Spaces of Global Capitalism: A Theory of Uneven Geographical Development." lst ed. London; New York, NY: Verso.

Ho, Justin Chun-Ting. 2020. "How Biased Is the Sample? Reverse Engineering the Ranking Algorithm of Facebook's Graph Application Programming Interface." Big Data and Society 7 (1): 2053951720905874.

Kaun, Anne, and Julie Uldam. 2018. "Digital Activism: After the Hype." New Media \& Society 20 (6): 2099-2106.

Kok, Saskia, and Richard Rogers. 2017. "Rethinking Migration in the Digital Age: Transglocalization and the Somali Diaspora." Global Networks 17 (1): $23-46$.

Laguerre, M. S. 2010. "Digital Diaspora: Definition and Models: Diasporas in the New Media Age: Identity, Politics, and Community." In Diasporas in the New Media Age: Identity, Politics, and Community, edited by Andoni Alonso and Pedro Oiarzabal, 49-64. Reno: University of Nevada Press.

Latonero, Mark, and Paula Kift. 2018. "On Digital Passages and Borders: Refugees and the New Infrastructure for Movement and Control." Social Media + Society 4 (1): 2056305118764432.

Lefebvre, Henri. 1991. The production of space. Oxford, OX, UK; Cambridge, Mass., USA: Blackwell.

Lefebvre, Henri. 2014. Critique of Everyday Life: The Three-Volume Text. Translated edition. London: Verso.

Leurs, Koen. 2014. "Digital Throwntogetherness: Young Londoners Negotiating Urban Politics of Difference and Encounter on Facebook." Popular Communication 12 (4): 251-265.

Leurs, Koen. 2015. Digital Passages: Migrant Youth 2.0: Diaspora, Gender and Youth Cultural Intersections. Amsterdam: Amsterdam University Press.

Leurs, Koen. 2019. "Transnational Connectivity and the Affective Paradoxes of Digital Care Labour: Exploring How Young Refugees Technologically Mediate Co-presence." European Journal of Communication 34 (6): 641649.

Leurs, Koen, and Kevin Smets. 2018. "Five Questions for Digital Migration Studies: Learning From Digital Connectivity and Forced Migration in(to) Europe." Social Media + Society 4 (1): 205630511876442.

Lim, Sun, Tabea Bork-Hüffer, and Brenda S. A. Yeoh. 2016. "Mobility, Migration and New Media: Manoeuvring through Physical, Digital and Liminal Spaces." New Media and Society 18 (10): 2147-2154.

Madianou, Mirca, and Daniel Miller. 2012. Migration and New Media: Transnational Families and Polymedia. Abingdon, Oxon; New York: Routledge. 
Makrygianni, Vasiliki, and Galis, Vasilis. Forthcoming. "Practices of radical digital care: narratives of queer and trans solidarity from Greece."

Margetts, Helen, Peter John, Scott Hale, and Taha Yasseri. 2016. "Tiny Acts of Political Participation." In Political Turbulence: How Social Media Shape Collective Action. Princeton: Princeton University Press.

Marino, Sara. 2015. "Making Space, Making Place: Digital Togetherness and the Redefinition of Migrant Identities Online." Social Media + Society 1 (2): 2056305115622479.

Massey, Doreen. 1994. Space, Place, and Gender. NED-New ed. Minneapolis: University of Minnesota Press.

Massey, Doreen. 1999. "Imagining Globalization: Power Geometries of TimeSpace." In Global Futures: Migration, Environment and Globalization, edited by A. Brah, M. Hickman, and Máirtin Mac an Ghaill. Cham: Springer.

Massey, Doreen. 2003. "Some_Times_of_Space." In Olafur Eliasson: The Weather Project, edited by Susan May, 107-118. London: Tate Publishing.

Massey, Doreen B. 2005. For Space. London: Thousand Oaks, CA: Sage.

Merisalo, Maria, and Jussi S. Jauhiainen. 2020. "Digital Divides Among AsylumRelated Migrants: Comparing Internet Use and Smartphone Ownership." Tijdschrift voor economische en sociale geografie 111 (5): 689-704.

Miller, Daniel, Jolynna Sinanan, Xinyuan Wang, Elisabetta Costa, Shriram Venkatraman, Juliano Spyer, Razvan Nicolescu, Tom McDonald, and Nell Haynes, eds. 2016. How the World Changed Social Media. London: UCL Press.

Mollerup, Nina Grønlykke, and Marie Sandberg. Forthcoming. "'Fast Trusting'-Practices of Trust During Irregularised Journeys to and Through Europe." In The Migration Mobile: Border Dissidence, Sociotechnical Resistance and the Construction of Irregularised Migrants, edited by Vasilis Galis, Martin Bak Jørgensen, and Marie Sandberg. Lanham: Rowman \& Littlefield.

Moores, Shaun. 2012. Media, Place and Mobility. Houndmills, Basingstoke, Hampshire; New York: Palgrave Macmillan.

Papataxiarchis, Evthymios. 2016. "Being 'There': At the Front Line of the 'European Refugee Crisis'-Part 1.” Anthropology Today 32 (2): 5-9.

Polson, Erika. 2015. "A Gateway to the Global City: Mobile Place-Making Practices by Expats." New Media and Society 17 (4): 629-645.

Roseneau, James N. 2003. Distant Proximities: Dynamics beyond Globalization. Princeton, NJ: Princeton University Press.

Sánchez-Querubín, Natalia, and Richard Rogers. 2018. "Connected Routes: Migration Studies with Digital Devices and Platforms." Social Media + Society 4 (1). Published electronically 1 January.

Shah, Nishant. 2019. "The Cog That Imagines the System: Data Migration and Migrant Bodies in the Face of Aadhaar." In The Sage Handbook of Media and Migration, edited by K. Smets, K. Leurs, M. Georgiou, S. Witteborn, and R. Gajjala, 465-476. Thousand Oaks, CA: Sage. 
Siapera, Eugenia. 2014. "Diasporas and New Media: Connections, Identities, Politics and Affect." Crossings: Journal of Migration and Culture 5 (1): 173178.

Siapera, Eugenia, Moses Boudourides, Sergios Lenis, and Jane Suiter. 2018. "Refugees and Network Publics on Twitter: Networked Framing, Affect, and Capture." Social Media + Society 4 (1): 205630511876443

Smets, K. (2018). The way Syrian refugees in Turkey use media: Understanding "connected refugees" through a non-mediacentric and local approach. Communications 43 (1): 113-123.

Smets, Kevin, Koen Leurs, Myria Georgiou, Saskia Witteborn, and Radhika Gajjala, eds. 2019. The Sage Handbook of Media and Migration. 1st ed. Thousand Oaks, CA: Sage.

Smith, Dorothy E. 1987. The Everyday World as Problematic: A Feminist Sociology. Boston: Northeastern University Press.

Stavrides, Stavros. 2010. Meteōroi Chōroi Tès Heterotētas. 1st ed. Athens: Ekdoseis Alexandreia.

Stavrides, Stavros. 2016. Common Space: The City as Commons. London: Zed Books.

Trimikliniotis, N., D. Parsanoglou, and V. Tsianos. 2014. Mobile Commons, Migrant Digitalities and the Right to the City. Cham: Springer.

UNHCR. 2015. "Emergency Appeal 2015: Winterization Plan for the Refugee Crisis in Europe (November 2015-February 2016)-World." UNHCR, 5 November 2015.

van Dijck, José. 2009. "Users like You? Theorizing Agency in User-Generated Content." Media, Culture \& Society 31 (1): 41-58.

van Dijk, Teun. 2018. "Discourse and Migration." In Qualitative Research in European Migration Studies, IMISCOE Research Series, eds. Evren Yalaz and Ricard Zapata-Barrero. Cham: Springer International Publishing: Imprint: Springer, 227-45.

Volkmer, Ingrid, ed. 2012. The Handbook of Global Media Research. Chichester, West Sussex: Wiley-Blackwell.

Witteborn, Saskia. 2012. "Forced Migrants, New Media Practices, and the Creation of Locality." In The Handbook of Global Media Research, Handbooks in Communication and Media, edited by I. Volkmer, 321-330. Chichester, West Sussex: Wiley-Blackwell.

Witteborn, Saskia. 2014. "Forced Migrants, Emotive Practice and Digital Heterotopia." Crossings: Journal of Migration and Culture 5 (1): 73-85.

Witteborn, Saskia. 2015. "Becoming (Im)Perceptible: Forced Migrants and Virtual Practice." Journal of Refugee Studies 28 (3): 350-367. 
Xie, Zhuoxiao, and Saskia Witteborn. 2019. "The Mobility-Migration Nexus: The Politics of Interface, Labor, and Gender." In The Sage Handbook of Media and Migration, edited by K. Smets, K. Leurs, M. Georgiou, S. Witteborn, and R. Gajjala, 453-463. Thousand Oaks, CA: Sage.

Yilmaz, Gaye Gokalp. 2013. "Tactics in Daily Life Practices and Different Forms of Resistance: The Case of Turks in Germany." Procedia-Social and Behavioral Sciences 82: 66-73.

Yuval-Davis, Nira. 2007. "Intersectionality, Citizenship and Contemporary Politics of Belonging." Critical Review of International Social and Political Philosophy 10 (4): 561-74.

Open Access This chapter is licensed under the terms of the Creative Commons Attribution 4.0 International License (http://creativecommons.org/licenses/ by $/ 4.0 /)$, which permits use, sharing, adaptation, distribution and reproduction in any medium or format, as long as you give appropriate credit to the original author(s) and the source, provide a link to the Creative Commons license and indicate if changes were made.

The images or other third party material in this chapter are included in the chapter's Creative Commons license, unless indicated otherwise in a credit line to the material. If material is not included in the chapter's Creative Commons license and your intended use is not permitted by statutory regulation or exceeds the permitted use, you will need to obtain permission directly from the copyright holder.

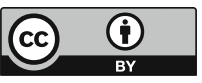

